Article

\title{
Networks Amongst Syrians: Situated Migrant Positionalities and the Impact on Relational Embedding
}

\author{
Francesca Speed ${ }^{1, *}$, Tracy Scurry ${ }^{1}$, Peter Edward ${ }^{1}$ and Mona Moufahim ${ }^{2}$ \\ ${ }^{1}$ Newcastle University Business School, Newcastle University, UK; E-Mails: f.speed2@newcastle.ac.uk (F.S.), \\ tracy.scurry@newcastle.ac.uk (T.S.), peter.edward@newcastle.ac.uk (P.E.) \\ 2 Stirling Management School, University of Stirling, UK; E-Mail: mona.moufahim@stir.ac.uk \\ * Corresponding author
}

Submitted: 15 May 2021 | Accepted: 19 July 2021 | Published: 15 December 2021

\begin{abstract}
This article employs Yuval-Davis concept of situated intersectionality to explore processes of relational embedding amongst Syrian migrants in the UK. By drawing on in-depth interview data from 31 men and women living in North East England, we explore how varying social categories-or positionalities-intersect and shape personal networks and feelings of attachment amongst Syrians. We show how wider structural contexts and systems of social relations shape migrants' sense of belonging and attachment which can serve to enhance or weaken opportunities for social and economic inclusion. The findings reveal how, for Syrian migrants, wider macro level contexts determine immigration and asylum routes which in turn shape place-specific opportunity structures that impact on micro individual level processes of relational embedding. We develop the term "migrant positionalities" as a social category to capture the multiple experiences of migration and asylum and the power dynamics that determine opportunity structures and processes of embedding. We contribute to the debates in this field by demonstrating how the wider structural context can lead to a multiplicity of immigration and asylum experiences for individuals, resulting in differences in support and rights that go on to shape processes of embedding and personal networks. By employing a situated intersectional lens, we also demonstrate how and why processes of relational embedding differ amongst migrants of the same nationality on the basis of social positionings such as ethnicity, class, and religion, that are situated in context, time, and space.
\end{abstract}

\section{Keywords}

migrant positionalities; relational embedding; situated intersectionality; Syrian networks

\section{Issue}

This article is part of the issue "In Good Company? Personal Relationships, Network Embeddedness, and Social Inclusion" edited by Miranda J. Lubbers (Autonomous University of Barcelona, Spain).

(C) 2021 by the authors; licensee Cogitatio (Lisbon, Portugal). This article is licensed under a Creative Commons Attribution 4.0 International License (CC BY).

\section{Introduction}

Scholarship highlights the positive role migrant networks play in the integration of forced migrants (van Liempt \& Nijenhuis, 2020). This links to shared linguistic, cultural, and religious capital, and the support and benefits gained from groups and initiatives led by, and for, migrant groups (Pincock et al., 2020). Yet, despite recognition of the limitations of migrant and co-ethnic networks (Gericke et al., 2018; Hynie et al., 2011; Kalter \& Kogan, 2014), dominant and homogenising assump- tions remain which overlook the varied challenges individuals face when navigating these networks. As a result, the nuances of individual needs and identities, and their implications for migrants' sense of belonging and attachment are often overlooked (Ryan, 2018). This has implications for processes of embedding and integration.

Embeddedness is central to discussions about migration (Lubbers, Verdery, \& Molina, 2020) based on the assumption that social networks help to develop a sense of belonging and facilitate access to resources which can support social and economic integration (Wessendorf 
\& Phillimore, 2019). However, recent work has emphasised the limitations of static conceptions of embeddedness as an achieved state (Lubbers, Molina, \& McCarty, 2020), reflecting a growing consensus that, if we are to move beyond simplistic assumptions of static network outcomes, it is valuable to consider processes of embedding to emphasise the complex relational dynamics that shape the ways in which networks are developed (for a discussion cf. Ryan \& Mulholland, 2015). This perspective highlights how those experiences are highly varied within and between migrant groups and can be affected by life events, life course (Lubbers, Molina, \& McCarty, 2020), and the varied rights and entitlements that diverse groups have (Ryan, 2018).

Whilst existing research acknowledges the impact of refugee status on network development (Bernhard, 2021; van Liempt \& Nijenhuis, 2020), there is limited empirical exploration of how different experiences of the immigration and asylum system, including the different legal statuses and rights, affect processes of embedding amongst migrants of the same nationality. Research has explored the importance of individual opportunity structures (Wissink \& Mazzucato, 2018) and the benefits of bonds based on shared hometown or regional identity (van Uden \& Jongerden, 2021) in the formation of individual networks, and the role of social categories in shaping migrant opportunities to form new relationships with host-country natives (Lubbers, Molina, \& McCarty, 2020). But more research is needed to explore how and why these personal networks differ amongst and across migrants of the same nationality and how these processes of embedding are shaped by wider structural factors (Ryan, 2018). This is reflected in calls for more intersectional analysis of migrant and forced migrant networks to understand how networks differ depending on the multiple social positionings held by individuals (Bilecen, 2021) and to explore the internal heterogeneity of "ethnic communities" (Lubbers, Verdery, \& Molina, 2020).

Within the literature, multiple and contested terminology is used to refer to migrant status ranging from forced migrants to globally mobile talent. However migrant status is not as straight forward as a category or label implies. Focusing on Syrian migrants in North East England, this article challenges the homogenising and dominant understanding that groups individuals into two distinct categories: migrant or forced migrants. For clarity we use the expression Syrian migrants throughout, as not all research participants identified as refugees. We draw on situated intersectionality (Yuval-Davis, 2015) to unpack the lived experience and the various social categories that impact individuals which allows for a more nuanced understanding of processes of embedding for migrants of the same nationality.

We contribute to the debates in this field by demonstrating how the multiplicity of immigration and asylum experiences lead to different opportunity structures, attachments, and rights for migrants that go on to shape processes of embedding and personal networks. We develop the term "migrant positionalities" to signify how, like other social positionings such as class or gender, migrant status and the implications of immigration and asylum pose both identity and power questions that shape belonging and attachment for Syrian migrants. We also show how applying a situated intersectionality framework demonstrates how ethnicity, class, religion, and migrant positionalities shape relational embedding and highlights the multiplicity of these positions influenced by time and space.

The next section briefly considers the theoretical framework. Following the methodology, the authors present thematic findings and engage in discussion. Finally, the authors summarise the article's findings and implications.

\section{Literature Review}

\subsection{Differentiated Embedding}

Ryan and Mulholland (2015, p. 142) define "embedding" as "a means of explaining the process through which social actors connect to and interact with a multiplicity of social, economic and political structures through various social relationships/social networks." The authors state that they purposefully use the continuous tense to reflect the contextual, dynamic, and differentiated processes that occur as migrants navigate, negotiate, and re-negotiate different domains over time.

In later work, exploring how Polish migrants in London were integrating in the local context and the influence of interpersonal relationships on decision making, Ryan (2018) argues that whilst the size and nature of personal networks is important, processes of "relational embedding" cannot be understood in isolation from wider structural contexts (e.g., political and legal frameworks for migrants and place-specific opportunities) that shape the positions and subjective experiences of individuals. Ryan therefore developed the concept of "differentiated embedding" as a multi-level framework (macro, meso, micro) for understanding how and why processes of embedding differ, not only between individuals but also within different domains (employment, family, friendships, locality) over time. This perspective enables a wider examination of the multiple and dynamic factors, beyond an individual's control, which shape processes of embedding. Focus to date has been on embedding of European migrants (Ryan, 2018), with limited exploration of the impact of varied immigration and asylum experiences on processes of embedding. Whilst Phillimore (2020) highlights the variation in integration outcomes for resettled refugees and asylumseekers, she calls for more examination of the impact of the different treatment individuals receive because of their immigration and asylum experiences. Therefore, a framework which enables an exploration of the widerstructural context provides a valuable lens for exploring 
processes of embedding for Syrian migrants in the North East of England, who have a multiplicity of immigration and asylum experiences. It allows us to study how the wider structural context impacts the sense of belonging and attachment and processes of relational embedding for this group.

However, individuals' sense of belonging and attachment are not only shaped by opportunity structures and experiences of immigration and asylum. Individual processes of embedding are also shaped by relational processes. Hite's (2003) work with firms unpacks how relationally embedded ties differ from each other due to the needs, interests, feelings, and emotions between people, leading to variations in networks. Networks are further compounded by the effort to embed and the quality of the ties. Hite (2003) challenges the dichotomous understanding of relational embedding and draws attention to the depth of networks based on variations in trust, intensity, and frequency of ties. Building on this, Ryan (2018) develops a more differentiated notion of relationality that explores the depth of trust and attachment which underpin embedding. This perspective argues that networks are linked to the people and places encountered in the varying social domains which are characterised by varied degrees of attachment, trust, and reciprocity. However, whilst recent work has started to explore how individual identity and various social categories shape migrant opportunities to develop networks and embed (Bilecen, 2021; Lubbers, Molina, \& McCarty, 2020), there is a need to further understanding of how this shapes relational embedding.

\subsection{Situated Intersectionality and Migrant Positionalities}

Intersectionality is the epistemological development of feminist standpoint theory developed by black feminists such as Kimberlé Crenshaw, Angela Davis, Audre Lorde, and Patricia Hill Collins. Initially developed to theorise black women's standpoint, intersectionality is an "analysis claiming that systems of race, social class, gender, sexuality, ethnicity, nation, and age form mutually constructing features of social organization" (Collins, 2000, p. 299) that shape forms of belonging and marginalisation. Hereafter, we employ the term "positionality" to refer to different standpoints and social categories. Recent network scholarship has drawn on intersectionality theory to problematise essentialist notions of ethnic migrant networks (Bilecen, 2021) and to contest the homogenous understanding of migrants. To contribute to this debate, we employ this theoretical framework to examine the intersecting power dynamics and various positionalities that influence experiences of embedding amongst Syrian migrants.

Specifically, we draw on situated intersectionality developed by Yuval-Davis (2015) who advocates its application to all and not just marginalised and racialised women. This lens allows for a multi-level approach (pp. 94-95), going beyond the social or relational by incorporating understanding of the temporal and spatial (Yuval-Davis et al., 2019). This includes how positions take on meaning-be they claimed or ascribed-at different times in different contexts. This approach argues that the "situated gaze, situated knowledge and situated imagination, construct differently the ways we see the world" (Yuval-Davis, 2015, p. 94), causing "contested, shifting and multiple" positionalities (p. 95). This means that "people positioned in the same social locations would often develop different identifications, meanings and normative attitudes and attachments to them" (p. 95). Focusing on situated gazes brings minority experiences from the margins to the centre and is useful when undertaking research with migrants of the same nationality to understand such differences.

\section{Methodology}

We draw on data from semi-structured interviews with thirty-one Syrians (19 women and 12 men), of varying immigration status, living in the North East of England gathered as part of a wider project where participants were asked to share their UK life story to unearth lived experiences of social and economic belonging. Trust and access were facilitated by pre-recruitment immersion (Mohebbi et al., 2018). The first author undertook an "extended stay" (Alfadhli \& Drury, 2020) by attending community and charity events with Syrians such as a Nowruz event and a public iftar event during Ramadan. The first author sent a call for participants, in Arabic and English, to individuals in her network via text and email. Using a snowballing approach, participants were recruited if they identified as Syrian adults living in the North East.

The research design meant that participants had entered the UK via various immigration routes: four were students in the UK and subsequently claimed asylum when the war began; one participant came to study with help from the Council for At-Risk Academics; one came as a student and found work; 13 participants came via the UN Refugee Agency (UNHCR) resettlement scheme; three participants came via family reunion (i.e., one of their family was already here, having previously claimed asylum); nine participants claimed asylum. Participants had resided in the UK between 10 months to 20 years and experienced multiple aspects of the immigration and asylum system ranging from asylum seeker, international student, sponsored employee, refugee, claiming Indefinite Leave to Remain, and gaining British citizenship. Participants identified as Arab Syrian, Kurdish Syrian, and Palestinian Syrian and were aged 18 to 70, coming from a variety of backgrounds ranging from university educated, professional workers to manual workers, homemakers, and caregivers. Interviews were in-person, lasted between 40 and 180 minutes and took place between April 2019 and February 2020 in locations chosen by the participants. 
To reduce language barriers and the implications of working with third-party interpreters, the first author (who already possessed conversational Arabic) undertook intensive Arabic language training for an eightmonth period prior to data collection. Learning the language alone is insufficient to bridge the insider-outsider dichotomy, nor guarantee access or trust. However, using a participant's native language is a powerful route to acceptance and allows for more authentic expression and increased nuance of meaning (Welch \& Piekkari, 2006). This research design allowed the first author a "third position" (Carling et al., 2014) whereby she was removed enough for participants to talk openly about challenges as she was perceived to be outsider as a white British non-Muslim, yet the language and extended stay facilitated connection and trust. The extended stay prior to data collection also helped the first author build knowledge of the communicative norms of the target population (Carling et al., 2014) whilst being exposed to variations in Syrian dialects and accents. To deepen mutual understanding, interviews moved between languages based on varied linguistic needs. We acknowledge that a limitation of this study is that some participants may have been more comfortable speaking in Kurdish.

Interviews were translated and transcribed into English, by the first author, in line with other studies focusing on refugees and multilingual communities (Ganassin \& Holmes, 2013). This necessitated listening to recordings several times and consulting online Arabic dictionaries to find the most accurate translation. This resulted in a deep awareness of the data which facilitated the analysis process. The first author kept a reflexive diary that helped navigate the complexities involved with multi-lingual interviewing and translating processes (Abalkhail, 2018). We used thematic analysis to make sense of the interview data. The data was coded using descriptive coding (e.g., neighbours), value coding (e.g., social-cultural values), and process coding (e.g., support from Syrians). Personal relationships and networks emerged as central themes. The second author checked the consistency and clarity of the coding by looking through the initial codes from the first author. An inductive, iterative approach was employed. Ethical approval was obtained for this project in advance of data collection and oral consent was gained from all participants. For anonymity, we use pseudonyms chosen by the participants.

A situated intersectionality framework was applied to the analysis phase, to challenge possible methodological nationalism and essentialist approaches to forced migration research. Drawing on McCall's (2005, p. 1773) notion of intercategorical complexity, we "provisionally adopt existing analytical categories to document relationships of inequality among social groups and changing configurations of inequality along multiple and conflicting dimensions." This meant provisionally looking at all Syrians as a shared ethno-national grouping whilst also searching for other social categories and dimen- sions that shape individual experience. By including other social categories, in addition to ethno-national ones, this approach provides a way of challenging the insider-outsider divide in migration research (Carling et al., 2014) and sets out to overcome some of the limitations of homogenising experiences to ethno-national positionalities only. We turned our focus to multiple social categories and the intersection of positionalities (Anthias, 2012) that came through the data, to remain open to the shifting nature of positionalities, meaning, and experiences.

\section{Findings and Discussion}

The coding analysis revealed two central themes that recurred in participants' identifications as migrants and in their understandings of their own personal networks in relation to the wider community. The first theme related to the wider structural context of embeddingnamely the immigration and asylum system-that impacted participants rights, networks, and feelings of belonging (Phillimore, 2020; Ryan, 2018). Here, we identify how three primary routes-education, resettlement, or asylum-differently shaped migrant positionalities and opportunity structures for embedding. The second theme related to the intersections of various other assigned and claimed positionalities-primarily relating to ethnicity, class, and religion. We use "claimed" to indicate individual agency in asserting their position (e.g., what it means to the individual to be a Kurdish Syrian) and "assigned" to signal how individuals impose positions onto "others" (e.g., how people view Kurdish Syrians). Here we identify how complex, multiple, and shifting positionalities differently shaped participants' feelings of belonging and attachment and processes of relational embedding with other Syrians. We explore these themes in the following sections.

\subsection{Migrant Positionalities and Opportunity Structures}

Processes of relational embedding were highly varied and differentiated, shaped by the rights, entitlements, and support individuals experience because of their different entry routes and legal status. We use the term migrant positionalities to signify the multiplicity of immigration and asylum experiences and the implications these positionalities have for individuals. We identify three broad groups in the migration experiences of participants: education route, resettled route, and asylum route. The education route indicates students who came to study, some of whom claimed asylum, while others secured a working visa post study or came with support from the Council for At-Risk Academics. The resettled route signifies those that came to the UK via the UNHCR's Vulnerable Persons Resettlement Scheme, which supports those affected by the war in Syria. The asylum route includes those that claimed asylum or family reunification. 
We will now consider how understanding these different migrant positionalities shaped processes of relational embedding and personal networks for these individuals. Building on Ryan (2018) and Phillimore (2020), we unpack how the wider structural context of different routes to migration can shape structural and relational processes of embedding for individuals.

\subsubsection{Education Route}

For participants in this route, processes of relational embedding were more likely to be shaped by factors and positionalities outside of their experiences of claiming asylum. Zara claimed asylum with her family during her PhD study. She says:

We have a support network, an existing support network in places outside of being refugees, so like when I go to university or it's like when I talk, I'm just another person so my experience is not summed up with being a refugee.

This highlights how, for Zara, the insecurity that the asylum system imposes was mitigated by the fact that she developed her network as a doctoral researcher at university and not as a refugee. This builds on Ryan and Mulholland's (2015) thesis, that different places present different opportunity structures, by highlighting the importance of the university as a social domain in developing participants' sense of belonging and facilitating professional relationships and economic embedding for students who claim asylum. Participants spoke of how the Education Route enabled access to networks beyond official refugee support and those experiencing hardship in the refugee community. This was seen to facilitate access to financial and emotional support that would otherwise be difficult for them to acquire. As Zara reflects:

I have a network outside of being refugee. Most of their [other refugees] network comes with being a refugee, their dealings with the council, their dealings with the job centre....They do have a social worker but all of it comes within the experience, within their experience of being a refugee. I have another parallel experience as it were.

This was echoed in the account of Amani, who also claimed asylum during her studies. She highlighted being able to draw on classmates for support not only with the course of study but also for her emotional wellbeing and for help with accommodation. These wider networks gave access to resources, to professional networks and to better opportunities to perfect the English language. These accounts demonstrate how the difficulties of claiming asylum were mitigated, to some extent, due to the differentiated nature of relational embedding linked to place (the university) and time (student first, then asylum experience; Ryan, 2018).
However, embedding within this route was not without challenge reflecting the varied opportunities to embed in different settings or domains (Ryan, 2018). Participants highlighted that, while there were benefits to a wider network, many in the Education Route did not have access to networks that could support them with their claim for asylum. Zara spoke of the lack of informed support from the university, citing the example of when the visa support team told her to leave the UK or return to Syria to renew her visa, neither of which is possible whilst claiming asylum. This perhaps reflects that the emphasis of university support tends to be on supporting refugees and asylum seekers into study via scholarships rather than supporting international students who, due to unforeseen circumstances back home, claim asylum during their studies. This group is therefore almost hidden and outside of asylum support networks, for example from local charities and councils, needed to navigate the asylum process.

\subsubsection{Resettled Route}

Within this route participants accounts highlighted how networks were predominantly formed with members of the Syrian resettled community. Whilst this group arguably had more structured support for embedding and developing networks (Phillimore, 2020), provided through a dedicated team at the local council, participants spoke of their frustrations with the support provided. As described by Samir:

The department responsible for Syrians can't absorb that much. Roughly every two months, or every three months, new families arrive. Sometimes, we go, me and my friend, we go to help. We help the council. Some support workers ask for help, always.... All employees at the Council do not have time. Sometimes they do not have time to reply on the phone.

Participants accounts highlighted how limited resource combined with increased demand meant that individuals waited many months to solve certain problems (e.g., issues with rent or heating). As illustrated by Zain: "I went twice and said this is the problem, but I didn't get an answer. Sometimes, people go and wait from the morning to the end of the allotted time... this is not the antidote to solve the issue."

As this network was the primary means of support for these individuals, limitations in the council's support meant some individuals were left isolated and excluded which led to disengagement. Sheear describes his experiences: "My relationship with the council is very weak, I don't go to the council a lot, or rather I don't go. Firstly, because of the language, secondly, I didn't find any benefit of going to the council." These "hollow ties" (Hite, 2003) reflected a lack of quality and depth in the relationship with the council which led to reduced frequency 
of interactions and diminished the opportunities for this relationship to positively influence processes of embedding (Ryan, 2018).

To facilitate networking and integration participants spoke of how the council asked some individuals to welcome new families by helping translate and showing them the local shops. Participants recognised the benefits of receiving this help when they first arrived and liked being able to give back by helping new arrivals later on. This also helped build a network outside of the council. However, it was restricted to resettled families where trauma, limited resources, and accumulative disadvantage were generally more prevalent. Participants spoke about the positives of this inter community support, however, many individuals highlighted the drawbacks for their English language development, fulfilling their job aspirations and developing their personal network outside of migrant communities. As a result, participants accounts reflected a sense of dislocation from the local population, with some individuals struggling to develop their confidence and to forge personal relationships outside of their immediate ties to other local resettled Syrians. Applying a differentiated embedding perspective to these experiences allows us to build on Phillimore's (2020) work on resettlement by exploring how the opportunity structures, resulting from structural embedding processes of resettlement, created some positive experiences of relational embedding whilst simultaneously having a limiting effect on embedding in other domains (e.g., work, wider local community; Ryan, 2018).

\subsubsection{Asylum Route}

Accounts of participants within the asylum route, clearly highlighted the impact of context for processes of relational embedding. Significant to these individuals' experiences was the wider geo-political context (Phillimore, 2020) and how that impacted policy and positioning of Syrian migrants within social and political discourses at the time they came to the UK to claim asylum. The ways in which this context was subject to change over time shaped participants' experiences and processes of embedding.

For example, Nour came to the UK with her family in 2014 before the peak influx of Syrian migrants. She claimed asylum upon arrival and her family waited 4 months for a decision. However, other participants who arrived after 2015 reported waiting much longer for their asylum decision - up to two and half years in some cases. Prolonged waiting negatively impacts on individuals' sense of security, self, and belonging. While the consequential impact on mental health (Löbel, 2020), along with restrictions on movement and finances, negatively impacts on their ability to build a personal network (Phillimore, 2020). As a result, embedding is negotiated differently as relationships to people and places change over time (Ryan \& Mulholland, 2015) due to the changes in status, forms of attachments, and feelings of security.

Another key feature participants identified was the role of personal resources-economic, social, and emotional-in facilitating access to different opportunity structures. Nour spoke of how, in comparison to those that come via the resettled route, her family had the resources, energy, and confidence to embed themselves and build networks which helped them quickly secure volunteering and work opportunities:

The ones that came by themselves they know that they could do it [secure employment]. They have some qualifications; they have something to depend on so they could do it. But these families, these people who came from the camps they were hopeless, they have nothing, and they really deserve the support and the help [referring to the resettled route].

Participants' accounts therefore emphasised the differences in experience for those that come without a pre-existing network and depleted resources (emotional, financial). For many in the asylum route, a difficult journey and subsequent challenges of claiming asylum and integrating, impacted on physical and mental health (Phillimore, 2020). Mohammed spoke of his exhaustion following a long and traumatic journey to get to the UK. He came as a single man without family and had to wait a long time to secure the right to work. The variations in the experiences within this route demonstrate the multiplicity of forms of embedding, that go beyond migrant status to include emotional, financial, and family support (Ryan, 2018). Looking back on the challenges he had faced over twenty years in the UK, Mohammed compared his experiences to those he knew who had come via the resettled route. He said it had taken him ten years to reach the stage that those individuals find on their first day in the UK (e.g., refugee status, right to work, benefits, a house, living with family). Despite his perceived accomplishments in both his personal and professional life in the UK, Mohammed's account demonstrates the subjectivity of embedding (Ryan, 2018). Mohammed also reflected on the differences between his experiences and some of his family members who came via family reunification:

When I came, I slept on the floor [street], when you [family member] came you sleep in my house, I give you money, I gave you a job, I took you to the Council, I get you a house, you know what I mean? I do all your paperwork, I take you to the solicitor, I do everything for you, so you didn't see anything.

In this section, we have demonstrated the multiplicity of migrant positionalities amongst and within the three identified routes. In doing so, we build on Phillimore's (2020) work, by highlighting the variations in structural processes, that determine migrant rights and 
experiences, as well as opportunity structures. We show how the uncertainty of immigration status for Syrians, and subsequent implications on mental health and feelings of belonging, impacts processes of embedding more broadly. Going beyond social domains and the quality and depth of social ties (Hite, 2003; Ryan, 2018), we demonstrate how structural processes of the immigration and asylum system lead to variations in relational embedding. Like other social positionings, such as class or ethnicity, migrant positionalities are claimed and assigned in varied ways, with implications for processes of embedding.

\subsection{Situated Positionalities and Relational Embedding}

Whilst the previous accounts highlight how routes to migration shaped the opportunities for relational embedding for Syrian migrants, accounts also highlighted how other social categories intersect to shape relational embedding. The situated intersectionality lens helps explore how participants develop different identifications and meaning despite a shared social location of "Syrian migrant." We find that positions are contested, shifting, and multiple depending on context, social, and temporal factors (Yuval-Davis, 2015).

\subsubsection{Situated Ethnic Positionalities}

We define ethnic positionality as the multiple and complex ways that we enact, claim, and position our ethniccultural selves. This was central to participants' sense of belonging and relational embedding before, during and after displacement. Participants accounts highlighted varying ethnic positionalities regardless of route and how they materialise in different ways across contexts and time. Sheear spoke about the oppression he faced as a Kurd in Syria compared to the acceptance he experienced in the UK:

The translator asked the nurse, where is the doctor from? The nurse smiled and said it is not custom to ask this question. By this I know that British people don't care if he was Arab, Kurdish, or Iranian. They know what a person does and how he works. I am in front of someone who is entirely different to me; yet he understands me. Effectively I could be myself. I noticed that here, they do not ask about one's identity, be it religion or language or whatever.

Sheear's account demonstrates a sense of acceptance and belonging, he felt he could be himself and that his Kurdish cultural-ethnic identity was respected in the UK, demonstrating how relationships can change over time and space (Ryan \& Mulholland, 2015). As a result, Sheear felt enabled to set up a local Syrian Kurdish group as a way of claiming and defining his ethnic positionality in the new context:
We need a Syrian Kurdish community group so that we can bring to society some of what we have lost in our country, for example learning the language, for example helping people who come here. Unfortunately, the ones that formed the community, did not think about that at all. They don't do anything. Every week we have a meeting, they talk about their cars, they talk [laughs]....Just this, nothing else, no culture, or education, nothing.

Sheear wanted to use the community group to celebrate Kurdish culture via educational programmes for children and events for families but felt that the rest of the group were content with meeting for coffee periodically. Sheear was claiming his ethnic positionality and shaping it in a way that had meaning to him with positive end goals for his community. He was assigning the same ethnic positionality to the fellow community group members but as his account highlights, ethnic positionalities are expressed and experienced differently amongst Syrian Kurds. Sheear understood these different attitudes to reflect differences in education and class background of the group members. These differences led to more shallow forms of embedding (Ryan, 2018) resulting in Sheear leaving the community group but remaining in contact by telephone. This intersectional lens helps unpack reasons for the variations in trust and quality of social ties (Hite, 2003). Unpacking ethnic positionalities as a starting point (Bilecen, 2021) helps demonstrate, in this case, that Syrian Kurdishness is expressed in several ways and influences personal ideas and goals and therefore processes of relational embedding and personal networks.

Furthermore, despite the network members coming via the same UNHCR resettlement programme, experiences of forced migration varied greatly. Sheear had been resettled to the UK with his wife, without any relatives or immediate family, therefore this community arguably played a more central role compared to the other members of the community who were resettled with their children, and in some cases extended family (for more discussion on the impacts of displaced family networks see Löbel, 2020). Sheear was also at a different stage in the life cycle to the other member of the group. Retired and without family in the UK, he had more time to invest in cultural and educational pursuits (Bernhard, 2021). Whereas the other network members were middle aged, with varying family responsibilities, in work or seeking employment. This illustrates how life stage (Ryan et al., 2021) and family networks shaped the nature and focus of processes of embedding and personal networks specifically.

A situated intersectional perspective shines light on the varying positionalities relating to ethnicity, stage in the life cycle, class, and experience of resettlement and how meanings are multiple and complex. In moving from Syria to the UK, meanings change through time and space, resulting in variations in the politicisation 
of ethnic positionalities. Sheear was able to "own" his Kurdishness in a new way, developing a network to celebrate and maximise the opportunities he saw this as presenting for the wider community, now and for future generations. However, he encountered challenges as other people's positionalities came to the fore so that ethnic-cultural identities were claimed and assigned in multiple ways demonstrating the differentiated nature of wider processes of embedding (Ryan, 2018).

\subsubsection{Politicisation of Religious and Class Positionalities}

Participants spoke about the varying political and religious affiliations across the Syrian community in North East England and how this impacted personal networks. Reemie explained how she felt excluded from any socialising with the Syrian community in the region and left out of the Syrian Students' Society at the university where she studied. Reemie felt that this was due to the perceptions of others about her religious and political views, based on the region of Syria that she came from:

When I joined the Syrian society, there was like if somebody gives birth, if somebody finishes the viva, they are always emailing congratulations to our friends blablabla who did... but the war had already started when I got married and they kind of divided and then I've never got any congratulations anything. I mean they just classify you, [if you're] coming from this part, so you are this, you are this. This is what I didn't like. I tried once to join, I tried. One Syrian guy he had a bad experience with something, I visited his wife. I mean I do this kind of initiatives, but I don't get any back.

This demonstrates the multiplicity of religious and political positionalities that are claimed and assigned within and across the Syrian community. The varying degrees of tolerance for religious minorities and varying religious practice is politicised. Uncertainty and fear of the regime and its network outside of Syria led to lots of speculation and suspicion, which was heightened in the new local as individuals' reasons for being in the UK were not always clear and fleeing or deserting Syria symbolised opposing the regime. This politicisation impacted processes of embedding and the personal networks participants forged across the Syrian community, and this highlights how wider macro dimensions of embedding can shape trust and reciprocity between individuals (Ryan, 2018). In Reemie's case, this treatment and rejection led her to have few Syrian friends in the UK, drawing heavily on networks with locals she forged through her son's playgroup and with the international student network at her university. An intersectional lens helps unpack the reasons for possible "hollow" forms of embedding characterised by low trust amongst Syrians (Ryan, 2018), calling into question the homogenisation of communities often grouped together by religion and political views.
Others also spoke of rejection by the local Syrian community. As Karen reflects:

There's something that they [Syrians] don't like about highly educated people. Like for me, I am open minded for everyone, you know. I have been told, "please don't talk to us because you don't wear hijab. I don't want you to affect my daughter's decision later." That was one of the women in my daughter's school and I was shocked because I am the one who is helping. But at the end, if I am looking from a very different perspective, I would see that's not because of the hijab, that's because I have higher qualification and yet they don't. So, this is how to attack me, is to take me from a perspective of religion because in my country or like in the Middle East, if you want to control someone you go through the religion perspective.

Karen's reflections highlight the tensions that individuals face in developing personal networks based on perceived class and religious identities assigned to them by other Syrians. Whilst unlike Reemie who said she was not religious; Karen was Muslim and spoke of how she was being excluded from networks because of a perceived deviation from cultural and religious practices around women's dress and behaviour. But for her, it was the underlying differences in education capital and socio-cultural norms that explained these differences. This illustrates the complexity of personal network development for this group as they seek to navigate their own beliefs, values and behaviours in multiple contexts which are heavily politicised (Yuval-Davis, 2015). Karen distanced herself from this network and, like Sheear, she explained that this was due to differences in educational background and cultural practices. Instead, she chose to engage with her family and the student network that her husband had developed where he studied. Karen's experience highlights how class and religious positionalities can reinforce separation and segregation within groups, perpetuating stereotypes. Going beyond relationships with host-country natives (Lubbers, Molina, \& McCarty, 2020), an intersectional lens helps unpack the reasons for variations in the quality and depth of relational embedding amongst migrants of the same nationality.

Yousef also spoke about a divide in the Syrian community which he links to educational background. He reflects on his voluntary efforts to run English classes in collaboration with the local council:

They [Syrians] said maybe he has benefits when he tries to build this community. I said it takes time from me and I am working. I do my best for my kids. I need them to grow up and have a good education, I need your kids [to do that] also, because we are one community. We should improve ourselves; we should be a positive community, we need to do the best in this community, we need education, we need to be good 
people in the community. But they said, "I don't need [this]." It's very hard to deal with them, very hard! So, I left this community, because I said they're not educated people.

He goes on to link being uneducated to religious and cultural deviance by explaining that some of these married men would "go to bars and meet girls." Like Karen, Yousef reflects on the intersections between class and religion demonstrating the multiple positionalities that influence personal networks amongst Syrians. Yet, unlike Karen, Yousef said that he would still help these individuals if they reached out, although he did not see them as friends. Yousef's position as an educated man from a middle-class background shapes his long-term goals for his children. He places more emphasis on education, the English language and securing a future for his children shaping the process of embedding and Yousef's personal networks. His efforts were met with suspicion and jealously, reflecting the different goals and attitudes that can be explained by the varying class positionalities. Unpacking class as a category contributes to understandings of individual opportunity structures (Wissink \& Mazzucato, 2018) and demonstrates how personal relations can become restricted by the ways that class structures work to reinforce disadvantage and exclusion.

\section{Conclusions}

In this article we have explored relational embedding amongst Syrian migrants, against a politicised immigration context in the UK. In developing the term "migrant positionalities," we highlight how processes of embedding are shaped by the rights, entitlements, and support Syrian migrants experience because of entry routes and legal status. We found that individuals who experienced the education route had access to opportunity structures, resources, and personal networks that helped secure jobs which significantly shaped processes of embedding. However, individuals faced immense strain juggling the demands of studying whilst navigating the asylum system, not being able to work and with limited specialised support due to their somewhat hidden circumstances. Furthermore, we demonstrate how the primacy of the "refugee" or "resettled" label assigned onto individuals in the resettled route, detracts from individual characteristics, experiences, and needs, and confines individuals to this assigned migrant positionality. For those claiming asylum, individual embedding was more subject to contextual and temporal factors -in particular timing of arrival in relation to the wider geopolitical landscape. Waiting longer for a decision and arriving alone with depleted emotional and financial resources negatively impacted mental health which restricted personal networks and integration. We show how assumptions of homogenised experiences overlook the diversity of the community. This has implications for policy and practice whereby a one-size-fits-all approach often excludes and overlooks those individuals who do not conform to the assigned label and associated behaviour.

Through a situated intersectional lens, we highlight the various social inequalities that are linked to the impact of state borders and explore the intersections of migrant status, class, ethnicity, stage of the life cycle, family composition, and religion. Applying this framework to Syrian migrant embedding has demonstrated the various migrant positionalities that shape individuals' access to different resources, capital, and networks. We find that there are various positionalities, that can be claimed individually or assigned onto others (within and between groups), and that these are subject to change over time and space. Through examining the accounts of participants, we highlight how processes of relational embedding are complex and shifting due to the multiple positionalities and the time and space needed for individuals to navigate, comprehend, and respond to this. This in turn impacts the quality and depth of relationships. Therefore, it is argued that an intersectional approach provides a more promising start for personal network analysis and migration studies. Going beyond the understanding that migrant personal networks are based on shared positionalities, we advocate Yuval-Davis' situated framework that calls upon temporal and spatial influences by highlighting the multitude of positionalities that impact the types of networks people want to invest in, have access to and how these differ within and across groups.

In this article, we have focused primarily on processes of relational embedding amongst Syrian migrants as a result of immigration and asylum experiences and other intersecting positionalities. We acknowledge participants' complex and dynamic relationships, with ties ranging from local to transnational across multiple social domains, but this was beyond the scope of the current article.

This article has three main practical implications. First, support for forced migrants, such as the resettlement scheme, often groups individuals by nationality or ethnicity with assumptions being made about common goals and identities that lead to nuances, and the importance of individual difference, being overlooked. Rather than presuming a common and shared position, recognising the complexities of migrant positionalities, and the impact of these on processes of personal network development and embedding offers an avenue for developing support mechanisms which are more inclusive of different possibilities. Second, we highlight some of the drawbacks of networks amongst migrants of the same nationality, notably how the variations in claimed and assigned positionalities, for example relating to class, ethnicity, and religion, lead to different individual aims, feelings of belonging and forms of relational embedding. We recommend that community groups should steer away from naming and defining themselves based on nationality (e.g., Kurdish Syrian group) and instead focus on shared goals (e.g., Kurdish history and language group). Finally, 
we demonstrate the need to strengthen specialised support within university networks for students applying for asylum.

\section{Acknowledgments}

We are grateful to all participants who took part in this research. This work was supported by the Economic and Social Research Council (grant number ES/P000762/1). The intensive language training prior to data collection was funded by the Northern Ireland and North East Doctoral Training Partnership. The first author was also a recipient of a two-month Anglo-Omani Society scholarship to study at Sultan Qaboos college in Manah, Oman.

\section{Conflict of Interests}

The authors declare no conflict of interests.

\section{References}

Abalkhail, J. M. (2018). Challenges of translating qualitative management data. Gender in Management, 33(1), 66-79. https://doi.org/10.1108/GM-03-20160029

Alfadhli, K., \& Drury, J. (2020). On the borders: Research with refugees of conflict. In Y. G. Acar, S. M. Moss, \& Ö. M. Uluğ (Eds), Researching peace, conflict, and power in the field. Springer. https://doi.org/10.1007/ 978-3-030-44113-5_8

Anthias, F. (2012). Transnational mobilities, migration research and intersectionality. Nordic Journal of Migration Research, 2(2), 102-110. https://doi.org/ 10.2478/v10202-011-0032-y

Bernhard, S. (2021). Reaching in: Meaning-making, receiving context and inequalities in refugees' support networks. The Sociological Review, 69(1), 72-89. https://doi.org/10.1177/0038026120945608

Bilecen, B. (2021). Personal network analysis from an intersectional perspective: How to overcome ethnicity bias in migration research. Global Networks. Advance online publication. https://doi.org/ 10.1111/glob.12318

Carling, J., Erdal, M. B., \& Ezzati, R. (2014). Beyond the insider-outsider divide in migration research. Migration Studies, 2(1), 36-54. https://doi.org/10.1093/ migration/mnt022

Collins, P. H. (2000). Black feminist thought. Knowledge, consciousness, and the politics of empowerment. Routledge.

Ganassin, S., \& Holmes, P. (2013). Multilingual research practices in community research: The case of migrant/refugee women in North East England. International Journal of Applied Linguistics, 23(3), 342-356. https://doi.org/10.1111/ijal.12043

Gericke, D., Burmeister, A., Löwe, J., Deller, J., \& Pundt, L. (2018). How do refugees use their social capital for successful labor market integration? An exploratory analysis in Germany. Journal of Vocational Behaviour, 105, 46-61. https://doi.org/10.1016/j.jvb.2017.12. 002

Hite, J. M. (2003). Patterns of multidimensionality among embedded network ties: A typology of relational embeddedness in emerging entrepreneurial firms. Strategic Organisation, 1(1), 9-49. https://doi.org/ 10.1177/1476127003001001217

Hynie, M., Crooks, V. A., \& Barragan, J. (2011). Immigrant and refugee social networks: Determinants and consequences of social support among women newcomers to Canada. Canadian Journal of Nursing Research, 43(4), 26-46. https://cjnr.archive.mcgill. ca/article/view/2326

Kalter, F., \& Kogan, I. (2014). Migrant networks and labor market integration of immigrants from the former Soviet Union in Germany. Social Forces, 92(4), 1435-1456. https://doi.org/10.1093/sf/sot155

Löbel, L.-M. (2020). Family separation and refugee mental health: A network perspective. Social Networks, 61, 20-33. https://doi.org/10.1016/j.socnet. 2019.08.004

Lubbers, M. J., Molina, J. L., \& McCarty, C. (2020). How do migrants' processes of social embedding unfold over time? Global Networks. Advance online publication. https://doi.org/10.1111/glob.12297

Lubbers, M. J., Verdery, A., \& Molina, J. L. (2020). Social networks and transnational social fields: A review of quantitative and mixed-methods approaches. International Migration Review, 54(1), 177-204. https:// doi.org/10.1177/0197918318812343

McCall, L. (2005). The complexity of intersectionality. Signs: Journal of Women in Culture and Society, 30(3), 1771-1800. https://doi.org/10.1086/426800

Mohebbi, M., Linders, A., \& Chifos, C. (2018). Community immersion, trust-building, and recruitment among hard to reach populations: A case study of Muslim women in Detroit metro area. Qualitative Sociology Review, 14(3), 24-44. https://doi.org/10.18778/ 1733-8077.14.3.02

Phillimore, J. (2020). Refugee-integration-opportunity structures: Shifting the focus from refugees to context. Journal of Refugee Studies, Article feaa012. https://doi.org/10.1093/jrs/feaa012

Pincock, K., Betts, A., \& Easton-Calabria, E. E. (2020). The global governed? Refugees as providers of protection and assistance. Cambridge Asylum and Migration Studies. https://doi.org/10.1017/9781108848831

Ryan, L. (2018). Differentiated embedding: Polish migrants in London negotiating belonging over time. Journal of Ethnic and Migration Studies, 44(2), 233-251. https://doi.org/10.1080/1369183X.2017. 1341710

Ryan, L., Kilkey, M., Lőrinc, M., \& Tawodzera, O. (2021). Analysing migrants' ageing in place as embodied practices of embedding through time: "Kilburn is not Kilburn anymore." Population Space and Place, 27(3), 1-10. https://doi.org/10.1002/psp.2420 
Ryan, L., \& Mulholland, J. (2015). Embedding in motion: Analysing relational, spatial and temporal dynamics among highly skilled migrants. In L. Ryan, U. Erel, \& A. D’Angelo (Eds), Migrant capital. Migration, diasporas and citizenship. Palgrave Macmillan. https://doi.org/ 10.1057/9781137348807_9

van Liempt, I., \& Nijenhuis, G. (2020). Socio-economic participation of Somali refugees in the Netherlands, transnational networks and boundary spanning. Social inclusion, 8(1), 264-274. http://dx.doi. org/10.17645/si.v8i1.2434

van Uden, J., \& Jongerden, J. (2021). Everyone is a possibility': Messy networks of refugees from Syria in Urfa, Turkey. Journal of Balkan and Near Eastern Studies, 23(2), 251-268. https://doi.org/10.1080/19448953. 2020.1867807

Welch, C., \& Piekkari, R. (2006). Crossing language boundaries: Qualitative interviewing in international business. Management International Review, 46(4), 417-437. https://doi.org/10.1007/s11575-0060099-1

Wessendorf, S., \& Phillimore, J. (2019). New migrants' social integration, embedding and emplacement in superdiverse contexts. Sociology, 53(1), 123-138. https://doi.org/10.1177/0038038518771843

Wissink, M., \& Mazzucato, V. (2018). In transit: Changing social networks of Sub-Saharan African migrants in Turkey and Greece. Social Networks, 53, 30-41. https://doi.org/10.1016/j.socnet.2017.03.005

Yuval-Davis, N. (2015). Situated intersectionality and social inequality. Raisons politiques, 2(58), 91-100. http://dx.doi.org/10.3917/rai.058.0091

Yuval-Davis, N., Wemyss, G., \& Cassidy, K. (2019). Bordering. Polity Press.

\section{About the Authors}
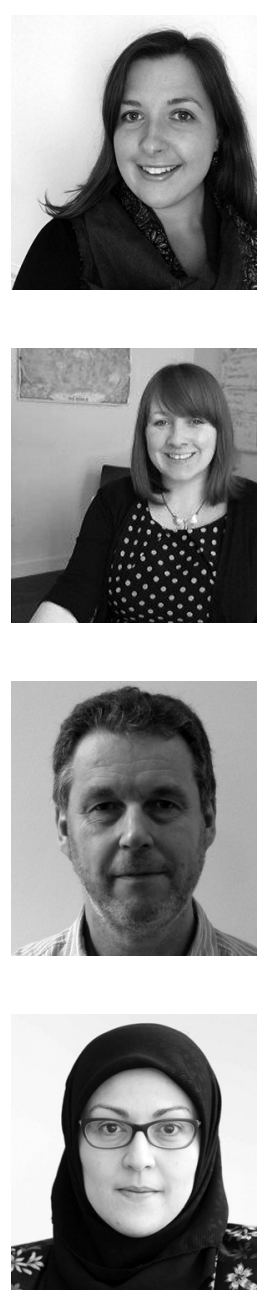

Francesca Speed is a NINE DTP postgraduate researcher at Newcastle University Business School, UK. Her research focuses on the lived experiences of forced migrants from an intersectional viewpoint, with particular focus on education and labour market progression. Her recent publication, in the Journal of Organizational Effectiveness People and Performance, looks at the role of talent intermediaries in supporting the access and development of talent from forcibly displaced backgrounds.

Tracy Scurry is a senior lecturer in human resource management at Newcastle University Business School. Her work seeks to reframe understandings about careers by demonstrating their multi-level and relational nature. She is interested in exploring how individual and societal factors interplay to influence career choices and outcomes, current research examines how imbalances and inequalities frame career experiences for different groups. Her work has been published in a range of journals including Gender, Work and Organisation, International Journal of HRM, and Studies in Higher Education.

Peter Edward is a lecturer in international business. His current research focuses on the relationship between business ethics, the changing role of business in society, and processes of social transformation in response to major societal challenges. His research has been included in publications by the United Nations Development Programme (UNDP) and policy documents by diverse NGOs, and has been used in evidence to the UK Government by the reformist think-tank the New Economics Foundation. His latest book is The End of Poverty: Inequality and Growth in Global Perspective (Palgrave, 2019).

Mona Moufahim is senior lecturer at the Stirling Management School at the University of Stirling in Scotland, UK. Her current research interests include identity, immigration, and extreme right politics, religious travel, and consumption. She is a member of the editorial board of the Journal of Marketing Management and of the Journal of Islamic Marketing. She is the chair of the Political Marketing SIG of the Academy of Marketing and a board member of the International Society for Markets and Development. 